\title{
Recycled-copper-filled epoxy composites: the effect of mixed particle size
}

\author{
Mohamad Nur Fuadi Pargi, Pei Leng Teh, Salmah Hussiensyah, Cheow Keat Yeoh and Supri Abd Ghani
}

\begin{abstract}
Background: The effect of mixed size of recycled-copper-filled epoxy composites on mechanical, electrical, thermal and physical properties was investigated.

Methods: The recycled copper was collected as a waste from the milling machine. The recycledcopper-filled epoxy composite was mixed using a mechanical stirrer.

Results: The effect of volume fraction of recycled copper of the epoxy composites were studied based on the flexural properties, coefficient of thermal analysis (CTE), electrical conductivity, hardness and density.

Conclusions: The incorporation of recycled copper has decreased the CTE of the composites. The flexural properties, electrical conductivity, hardness and density of the composites increased with increasing volume fraction and filler loading.
\end{abstract}

Keywords: Recycled copper; Epoxy; Mechanical; Electrical; Thermal; Physical properties

\section{Background}

Recently, conductive polymer has received considerable interest as a solder replacement in flip chip packaging because there is a significant reduction in pitch, weight and volume and increased environmental compatibility (Sun 2001). Conductive polymer materials, which have both strong conductivity and the properties of polymers, are widely used in electronics and biosensors (Glouannec et al. 2008). Polymer materials are often used as insulators because of their low thermal and electrical conductivity. This has led to limitations of the use of polymer in electrical and electronic applications (Boudenne et al. 2005).

However, the introduction of conducting polymer composites $(\mathrm{CPCs})$ has initiated the application of polymers in many fields of engineering especially in the electrical and electronic applications. Indeed, conducting polymer composites have shown its crucial importance in many useful and high-end applications since few decades ago, and it continues to become a choice of selection in various industries especially in electrical and electronic applications (Ramasubramaniam et al. 2003). Conducting polymer composites involve incorporating a conductive filler into the polymer matrix. These

* Correspondence: moss_fuadi@yahoo.com

Universiti Malaysia Perlis, 02600 Jejawi, Perlis, Malaysia composites are produced from the blending of an insulating polymer matrix with electrical conductive fillers (carbon black, carbon fibre, metal particles) show many interesting features due to their electrical resistivity variation with thermal solicitations ( $\mathrm{Li}$ et al. 2011).

A conductive polymer composite can be produced by loading an insulating polymer matrix with a sufficient volume of electrically conductive filler, so that interconnectivity of conductive pathways exists throughout the bulk material (Feller et al. 2004). The reinforcement phases, especially the metal particles in epoxy resin, are usually discrete particles, which lead to discontinuous heat conduction paths (Ji et al. 2014). Factors such as the size, shape, chemistry and aggregation behaviour of filler particles must be considered in conjunction with the thermodynamic and rheological properties of the polymer matrix and the processing conditions employed (Burden et al. 1998). The main significant factor is the filler distribution within the matrix, which can result from processing conditions (temperature, shearing, viscosity and orientation), formulation (filler content, molecular weight and crystallinity of the polymer, solubility parameters, particle/particle and particle/macromolecule interactions) and spatial parameters (shape factor of the conducting particles, exclusion domains in which particles cannot go) (Feller et al. 2004).

\section{Springer}

(c) 2015 Pargi et al.; licensee Springer. This is an Open Access article distributed under the terms of the Creative Commons Attribution License (http://creativecommons.org/licenses/by/4.0), which permits unrestricted use, distribution, and reproduction in any medium, provided the original work is properly credited. 
Polymer-based electrically conducting composites have several advantages over their pure metal counterparts including lower cost, ease of manufacture, high flexibility, reduced weight, mechanical shock absorption ability, corrosion resistance and conductivity control of many fields of engineering, such as for electromagnet interference (EMI) shielding, safe packaging, corrosion protection, electrostatic discharge (ESD) control, conductive adhesive etc. (Teh et al. 2011; Rupprecht 1999). This interest arises from the fact that the electrical characteristics of polymer composites are closed to properties of metals, whereas the mechanical properties and processing methods are typical for plastic (Mamunya et al. 2002). In addition, since conducting polymer composites have the advantages of being less costly and lighter weight compared to metals, they are positioned to play an increasingly important role in affairs of mankind, specifically in the area of electronic and electrical conductivity (Tavman 1996). Polymer composites filled with metal are of interest for use; one main parameter determining $\mathrm{CPC}$ properties is the conductive pathway structure, depending on many parameters such as filler content $(\phi)$, surface free energy of the filler and the matrix, crystallinity, reticulation and exclusion volume, i.e. zones where carbon black is concentrated (Gazotti et al. 1999).

Metal-filled polymer composites are getting acceptance for the past few years, mainly due to concerns about the environment (Lira and Córdoba de Torresi 2005). The most general approach to describe the charge transport in conducting polymer composites in relation to the content of conducting particles is provided by the percolation theory (Battisti et al. 2010). When a polymer matrix is filled with dispersed conductive filler, the composite prepared gains a conductivity value. When the filler volume fraction reaches a critical value, the so-called percolation threshold, an infinite conductive cluster, is formed, and the composite shows a drastic increase in the conductivity value (Stauffer and Aharony 1985). In such networks, there is either direct contact between adjacent particles, or sufficiently small gaps between them, to enable a mechanism of quantum mechanical tunnelling conductivity.

The percolation threshold is strongly influenced by the geometrical characteristics of the conductive filler, such as aspect ratio and particle size distribution, so that an increase in their value may dramatically drop the filler concentration required to achieve conduction in a given polymeric matrix (Teh et al. 2011). The transfer conditions of the electric charge and heat flow determine the electrical and thermal conductivity level in the heterogeneous polymer-filler system, in which the conductive phase is formed by dispersed metallic or carbon filler (Jaafar @ Mustapha 2008).

An important feature of metal-filled polymeric materials is a transition from insulating to conducting behaviour over a narrow range of the volume fraction of the conductive filler. The critical volume fraction of the filler associated with the transition has been variously reported to range from about 5 to $40 \mathrm{vol} \%$ metal filler. The value of the critical concentration depends on the shape, size and orientation of the filler and on the method of fabrication of the composite material (Michael et al. 1985). Since metals are the quintessential conductors of electricity, it is not surprising that they have been used as fillers to create conductive plastic composites (Luyt et al. 2006). In comparison to conductive carbon, the resistivity of metals is much lower, while their densities are higher (Bhattacharya 1986). However, density advantage is insignificant when the electrical conductivity is centred.

Generally, the metal with high electrical conductivity will become the choice of selection in producing conductive composites. Although silver is a better electrical conductor than copper, copper has been preferred owing to its more economical reason compared to costly silver (Bhattacharya 1986).

Copper is $100 \%$ recyclable. Virtually all products made from copper can be recycled. Due to high product value and some related environmental issues, copper is recycled where there is possible. Using recycled copper can save energy as copper extraction is very energy consuming. Consequently, it can save landfills by reducing the amount of waste copper (Cleveland 2004). The electrical conductivity of the recycled copper may differ from the pure one. In fact, there are many sources of recycled copper ranging from copper piping of the air conditioning units, scrap electrical wiring to door and window frames. Besides, many machining operations such as milling, grinding, drilling etc. produce waste which can be recycled. In this research, waste copper from milling machine is collected and recycled to produce copper-filled epoxy composite. The epoxy resins have been extensively used in many industrial fields such as adhesives, constructions, coating and insulation materials for electric devices due to their good balance of properties such as excellent moisture, solvent and chemical resistance, low shrinkage after cure, superior electrical and mechanical properties and good adhesion to many substrates (Tao et al. 2007). Epoxy matrix composites are prone to impact damage which includes failure modes such as transverse cracking, delamination, fibre/matrix debonding and fibre fracture, all limiting their uses for many structural applications (Wong et al. 2010).

\section{Methods}

\section{Sample preparation}

Recycled-copper-filled epoxy composites were prepared according to the volume fraction method by using the formula: 


$$
V_{\mathrm{f}}=\frac{W_{\mathrm{f}} / \rho_{\mathrm{f}}}{W_{\mathrm{f}} / \rho_{\mathrm{f}}+W_{\mathrm{m}} / \rho_{\mathrm{m}}}
$$

where $V_{\mathrm{f}}$ is the filler volume fraction, $W_{\mathrm{f}}$ is the weight of the filler, $\rho_{\mathrm{f}}$ is the density of the filler, $W_{\mathrm{m}}$ is the weight of the matrix and $\rho_{\mathrm{m}}$ is the density of the matrix.

The recycled copper was milled into finer powder using different milling hours for 24 and $72 \mathrm{~h}$, respectively. Samples of epoxy composites filled with $0,10,20$, 30 and $40 \mathrm{vol} \%$ of recycled copper were prepared, respectively. First, the epoxy resin (D.E.R 331 was supplied by Eurochemo Sdn. Bhd., Prai, Malaysia) with required weight was measured and poured into a mould. Then, the recycled copper filler was added, and the mixture was stirred using a mechanical stirrer until the mixture was homogeneous. A hardener (a polyamine clear hardener was supplied by Eurochemo Sdn. Bhd.) of about $60 \mathrm{phr}$ by weight was added and the mixture was stirred again. The mixture was then poured into the mould, and the composite was left in the vacuum oven at room temperature for about $20 \mathrm{~min}$ to remove the bubbles. Then, it was cured using air oven at $100^{\circ} \mathrm{C}$ for $1 \mathrm{~h}$. The samples were polished using a polishing machine to obtain samples with smooth surfaces prior to testing.

Coefficient of thermal expansion (CTE) of the composites was determined by using a L75 platinum series dilatometer (Linseis Inc., Robbinsville, NJ, USA). The dimensions of the sample were $8 \mathrm{~mm}$ in diameter and with a maximum thickness of $20 \mathrm{~mm}$. Testing was conducted at a heating rate of $5^{\circ} \mathrm{C} / \mathrm{min}$ from a temperature of $0^{\circ} \mathrm{C}$ to $200^{\circ} \mathrm{C}$. A flexural property was carried out by using a universal testing machine (UTM) with a crosshead speed of $0.5 \mathrm{~mm} / \mathrm{min}$ with a sample dimension of $3-\mathrm{mm}$ thickness and 6-cm length. The electrical conductivity is the reverse of the resistivity values; it can be measured by using a GDM 352A multimeter (GW Instek America Corp, Chino, CA, USA) with a sample dimension of $1-\mathrm{cm}$ diameter and $0.3-\mathrm{cm}$ thickness. The hardness value of the composites was obtained by using a Vickers hardness tester FV-700e (Future-Tech Corp., Tokyo, Japan) where the composites were indented with a load of $1 \mathrm{~kg}(9.8 \mathrm{~N})$ for $15 \mathrm{~s}$. The density of the composites was determined by using a AccuPyc 11340 gas pycnometer (Micromeritics Instrument Corporation, Norcross, GA, USA) where the dimension is $8 \mathrm{~mm}$ in diameter and $20 \mathrm{~mm}$ in thickness.

\section{Results and discussion}

\section{Recycled copper particle size}

In this research, the recycled copper waste chips that were collected from the milling machine were milled into powders for two sets of milling hours which were 24 and $72 \mathrm{~h}$ at a speed of $250 \mathrm{rpm}$. Table 1 shows the results of average powder particle sizes of the recycled

$\begin{aligned} & \text { Table } \mathbf{1} \text { The particle sizes of the recycled copper powders } \\
& \text { at different } \text { milling times }\end{aligned}$
\begin{tabular}{lll}
\hline Milling time (h) & $\begin{array}{l}\text { Particle size } \\
\text { distribution }\end{array}$ & $\begin{array}{l}\text { Average powder particle size } \\
\text { of recycled copper }(\boldsymbol{\mu m})\end{array}$ \\
\hline 24 & Bimodal & 300 to 400 \\
72 & Monomodal & 10 \\
\hline
\end{tabular}

copper for different milling times. It shows that when the milling time increases, finer powder of the recycled copper was obtained. During ball milling, powders were trapped between colliding balls and were subjected to high stress. Consequently, powders were subjected to a severe plastic deformation which exceeds their mechanical strength (Xu et al. 2006). Thus, when the milling time or processing time was increased, the finer powders were obtained. Indeed, in most cases, the rate of particle refinement (i.e. particle size and/or crystallite size) is roughly logarithmic with the processing time or ball-to-powder ratio (Xu et al. 2006).

Figure 1 shows the particle size distribution obtained through a Malvern particle size analyser (Malvern Instruments, Malvern, UK). When the powders were milled for longer hours, the multimodal distribution was gradually shifted to monomodal distribution, with a significant reduction of the volume percentage of coarser particles (around $350 \mu \mathrm{m}$ ). Owing to a higher stress subjected to the powders at longer milling hours, a more efficient milling operation was performed, changing the form of the powder from a mixture of fine and coarse particles to completely fine particles.

\section{Coefficient thermal expansion}

The effect of different particle sizes which are coarse, fine and mixed at different recycled copper filler loading on coefficient thermal expansion was investigated. From Figure 2, it was found that epoxy composites with mixed particle size have the lowest CTE value followed by fine and coarse, respectively. The addition of fine filler strengthens the composites since it provides less gap between the filler. Therefore, the filler packed closely and the gap between the filler becomes smaller. Reducing the particle size to a smaller level is assumed to reach a significant efficiency. Fine particles seem to contribute better to the property improvement (Klaus et al. 2005). The thermal properties of polymers can be significantly enhanced by the addition of fine filler (Osman 2010). Fine particulate filler has played a vital role in the development of commercially viable polymers. They not only provide significant cost reduction but also improve thermal behaviour (Willis and Masters 2003).

Coarse filler in composite structure tends to have bigger gap in between them. It allows the composites to expand more when thermal was supplied. The 

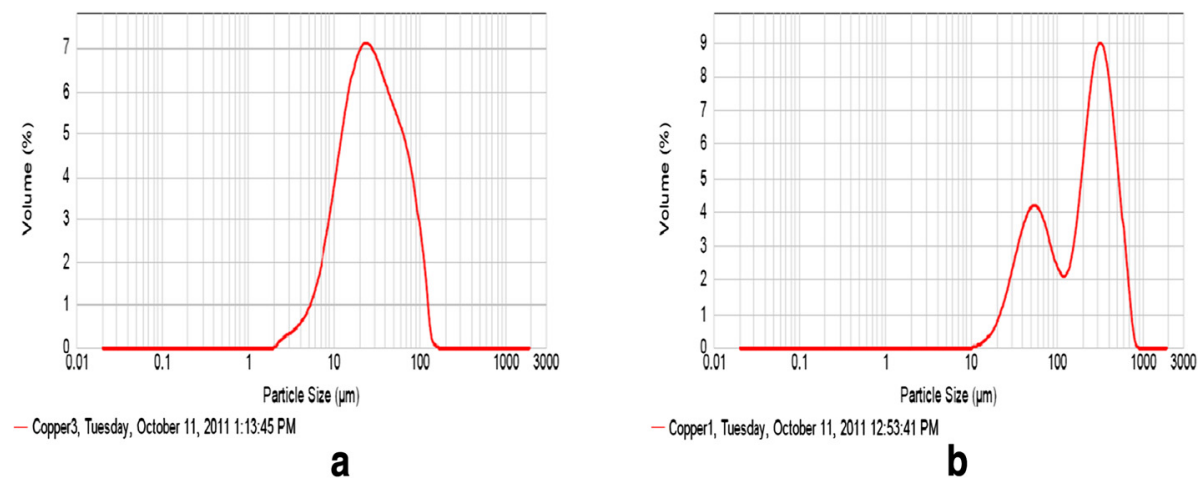

Figure 1 Particle size distribution. The particle size distribution for recycled copper powder which was milled for (a) $72 \mathrm{~h}$ and (b) $24 \mathrm{~h}$, respectively.

properties of filler-filled composites are determined by the characteristic of its components, composition, structure and interfacial interaction (Erika and Janosmoczobelapukanszky 2004). The fine particle filler has better interaction since it has better orientation. Although filler content and filler size significantly influence the properties of polymer composites, any changes in polymer/filler interaction also have considerable effect on these properties. This effect depends both on the size of the contacting surfaces and on the strength of the interaction.

The addition of recycled copper was decreasing the CTE value of the epoxy composite. By adding the recycled copper to the matrix, it will reduce the CTE value of the composites. At a higher $\mathrm{Cu}$ content, the CTE decreases substantially. The high heat capacity and thermal conductivity of $\mathrm{Cu}$ causes these particles to quickly reach a higher temperature than the surrounding matrix (through the percolation pathways observed for high $\mathrm{Cu}$ content composites) (Luyt et al. 2006). From the figure, it shows that the epoxy composites with mixed filler particle size have lower CTE value than 10 $\mu \mathrm{m}$ in particle size. The composite CTE decreases linearly with the filler volume fraction. The formation of a conductive network in the composites should be more likely with small and coarse particles. The effective thermal conductivity of the composites filled with mixed with smaller and larger particles is higher than the one with the larger particles at a given volume fraction (Boudenne et al. 2005).

\section{Flexural strength}

Figure 3 shows the flexural strength of epoxy composites filled with coarse, fine and mixed filler sizes at different recycle copper filler loading. The debonding

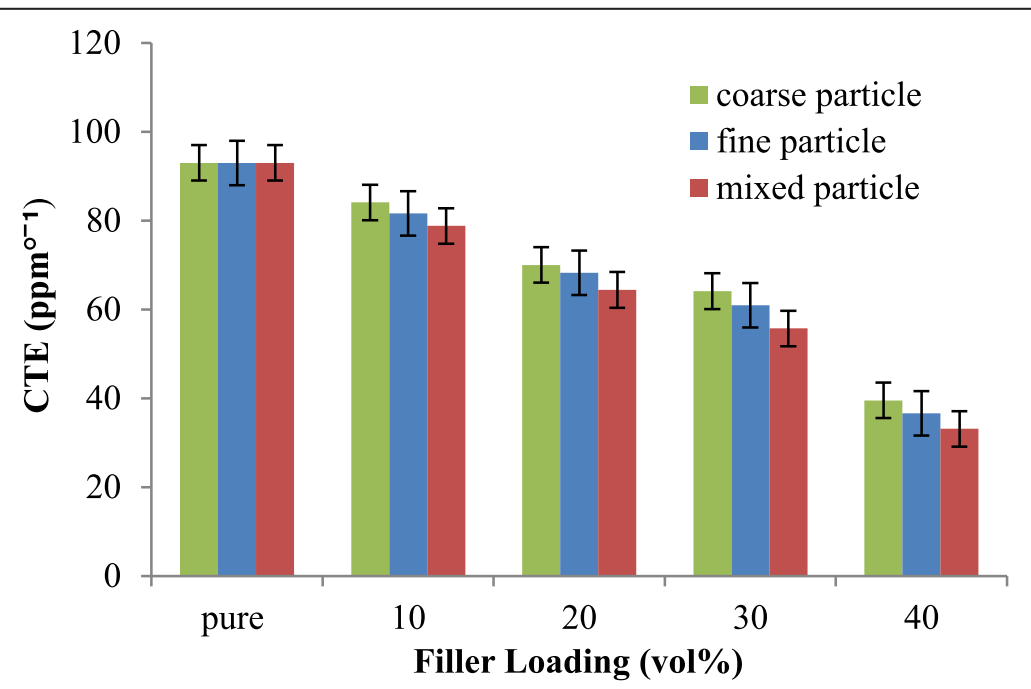

Figure $\mathbf{2}$ CTE of epoxy composites. The epoxy composites are filled with coarse, fine and mixed particle sizes at different recycled copper filler loading. 


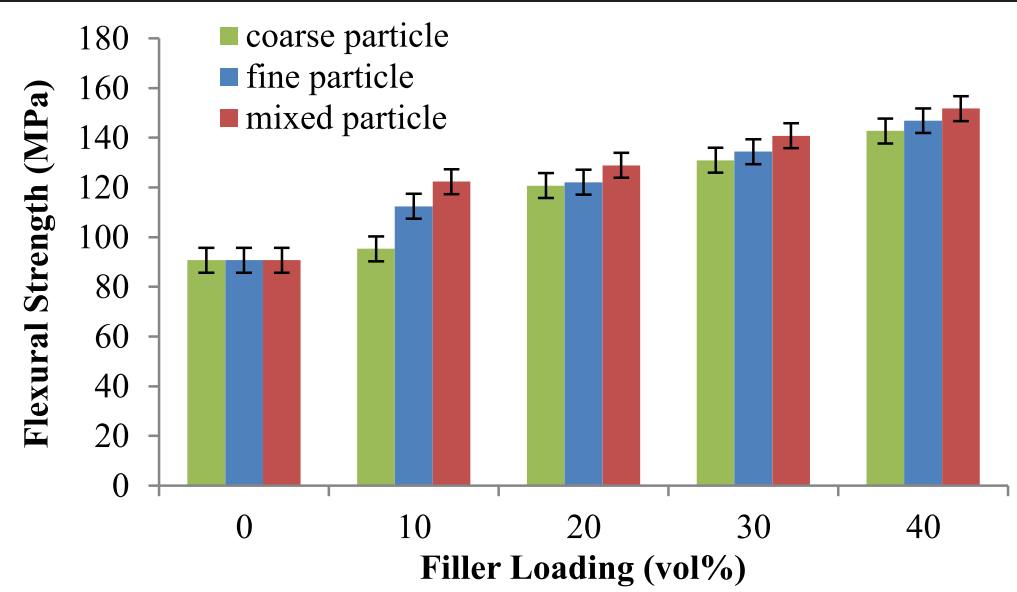

Figure 3 Flexural strength of epoxy composites. The epoxy composites are filled with coarse, fine and mixed particle sizes at different recycled copper filler loading.

stress is one of the key parameters of particulate-filled composites, and it is strongly related to particle size (Luyt et al. 2006). Smaller particle filler size enables the composites to have good strength since it provides a compact structure. In the presence of particles, the stress fields change locally and thus may suppress cavitational deformation modes at least to some extent and instead may initiate local shear yielding of the surrounding matrix (Dekkers and Heikens 1985). The fine filler particle caused fewer voids in the composite structure. It was shown in earlier work that smaller particles are not desirable, for they require more polymers for effective binding, resulting in a lower flexural strength. Too large particles, on the other hand, act as discontinuities, again lowering the flexural strength. The difference between the size groups, however, is most likely due to differences in packing density. Denser packing, i.e. a smaller composite porosity, will result in a higher flexural strength.

The fine filler fulfilled the gap that is present between the coarse filler which is shown in Figure 4. Therefore, the composites become more rigid. Two different sizes of particle composition enabled significant increase in fracture behaviour of the composite for a given constant volume fraction. This is because of a more uniform particle size distribution due to the presence of large particles which reduced the particle agglomeration. Moreover, particles with larger sizes can induce easier crack propagation owing to the stress concentration in particulate-reinforced composites. Since epoxy composite with mixed particle size gives better filler packing, the dispersion of the filler throughout the epoxy composites is well-dispersed. A broad size distribution will result in larger maximum packing friction than with monodisperse spheres, as small particles can fit into spaces around larger ones. The addition of two different sizes as a filler in the composites leads to the assembling of the sub-micron particles in the polymer medium from the balance between particle-particle and particle-polymer interaction (Kitey and Tippur 2005). The flexural strength and modulus of epoxy composites improved with the incorporation of mixed copper particle; however, as shown in Figure 4, it can be seen clearly that there are gaps between the epoxy and copper particle (as shown in dotted circles). It can be concluded that interfacial bonding between the copper particle and epoxy can be further improved.

\section{Flexural modulus}

The flexural modulus of epoxy composites filled with coarse, fine and mixed particle sizes at different filler loading was also investigated as shown in Figure 5. The flexural modulus is found to increase with decreasing particle size. Strongly bonded fillers show higher flexural modulus since weakly bonded particles act as sources of inherent flaws provoking crack initiation. When the particle size increases the crack deflection, debonding and particle fracture increase. The size and distribution of filler particles play a significant role, since the filler is much stiffer than the polymer matrix, and the stiffness increases with the increasing filler content. The propagation of the crack is impeded by the stiff particles that act as obstacles slowing down the advancing of the crack front, whereas the latter takes place in a localised shear yielding, with the formation of damaged zone due to crack diversion, particle fracture and debonding of the particle/matrix interface (Luyt et al. 2006).

From the figure, it indicates that epoxy composites with mixed particle size of recycled copper filler give a 


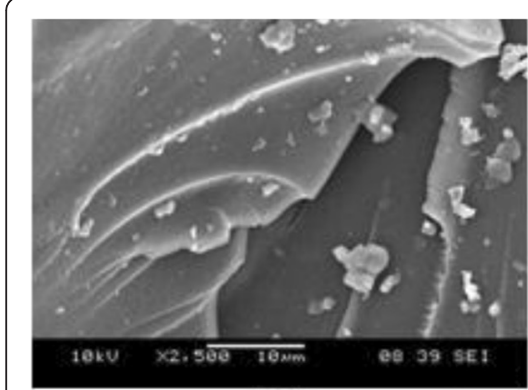

(a)

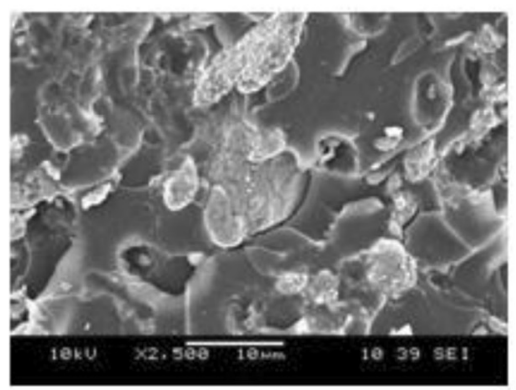

(d)

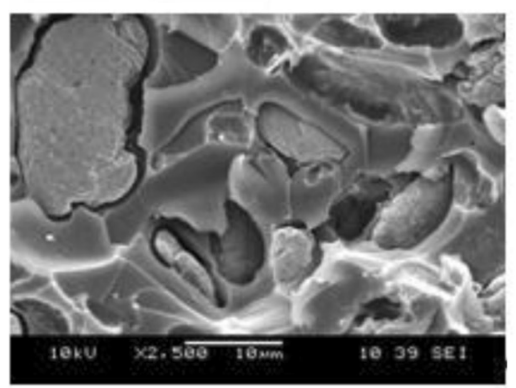

(g)

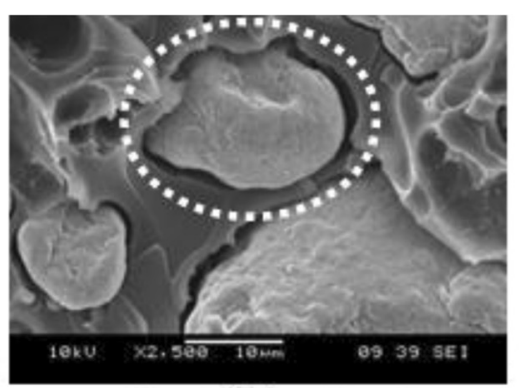

(b)

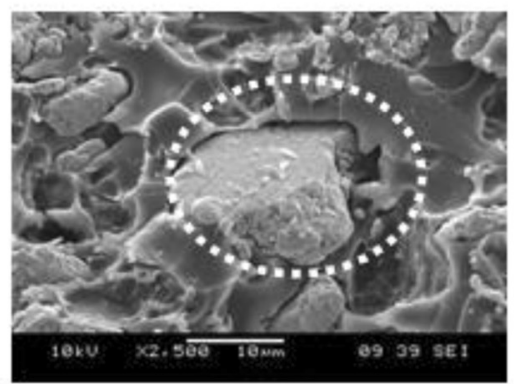

(e)

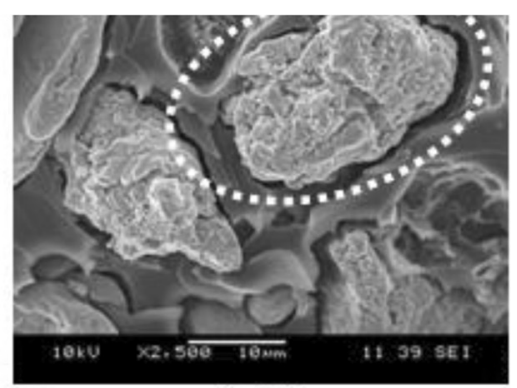

(c)

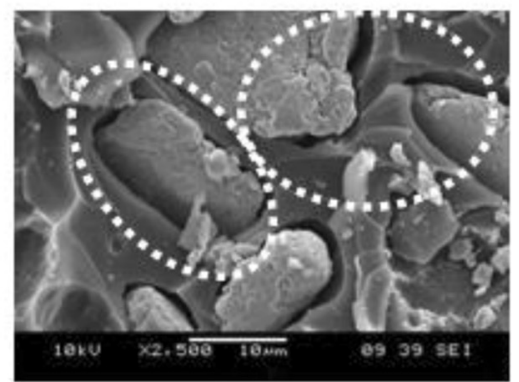

(f)

Figure 4 SEM of epoxy composites. SEM of epoxy composites with recycled filler content at (a) 0 vol\%, (b) coarse 20 vol\%, (c) coarse 40 vol\%, (d) fine 20 vol\%, (e) fine 40 vol\%, (f) mixed 20 vol\% and (g) mixed 40 vol\%, respectively.

higher flexural modulus than with a $10-\mu \mathrm{m}$ particle size of recycled copper filler. Internal defects and imperfect interfaces are well known to exist in composites. The incorporation of such phenomena into the general theory requires modification and relaxation of the continuity of displacements between the constituents. The imperfect interface bond may be due to the compliant interfacial layer known as interphase or interface damage, which may have been created deliberately by coating the particles. Moreover, the strength of the bond at the interface controls the mechanical response and fatigue life of the composite.

\section{Electrical conductivity}

From Figure 6, it shows the electrical conductivity of epoxy composites filled with coarse, fine and mixed filler particles at different filler loading. The composites that consist of an insulating matrix and fine conductive filler have generated significant research interest, mostly due to their electrical conductivity. The conductive particles are in contact, inside the insulating matrix; percolation paths should exist through the entire system and thus metallic type conduction occurred (Psarras 2006). The fine filler will have a compact structure compared to coarse particle. Therefore, the percolation threshold effect is about to happen. The electrical performance of matrix-conductive filler composites is sufficiently affected by the size of the inclusions (Psarras 2006).

The addition of metallic increases the electrical conductivity of the epoxy composites. The electrical performance is directly related to the permittivities and conductivities of their constituents, the volume fraction 


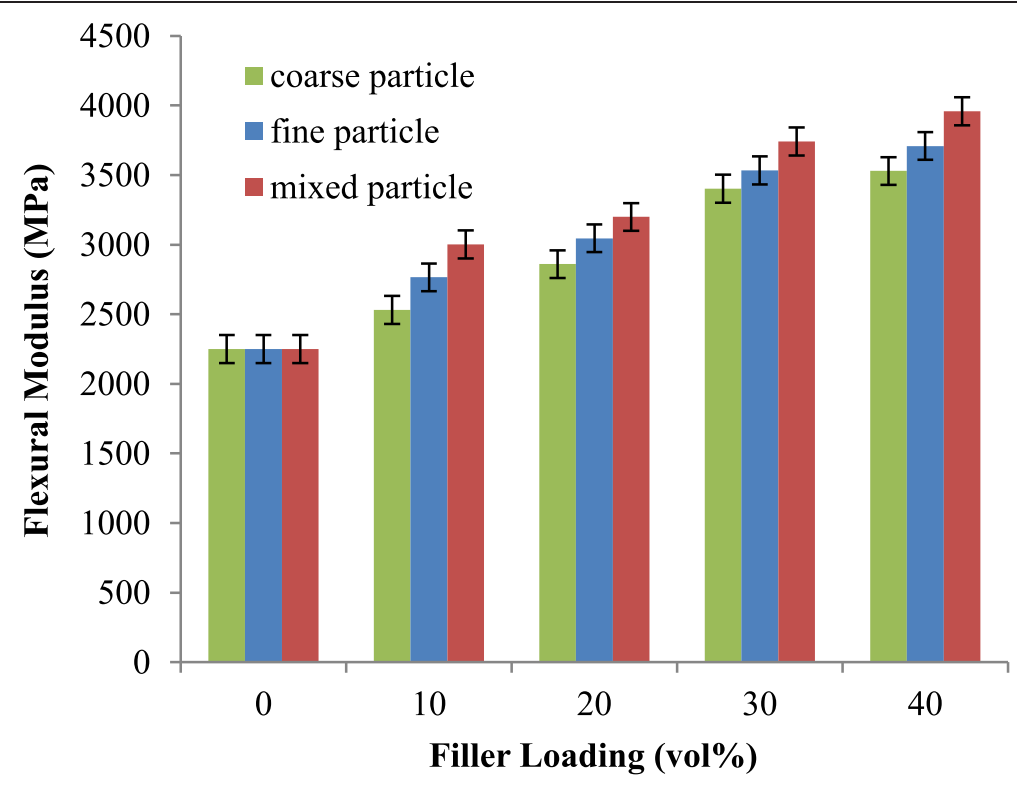

Figure 5 Flexural modulus of epoxy composites. The epoxy composites are filled with coarse, fine and mixed particle sizes at different recycled copper filler loading.

of the filler and the size of this particle. The conduction behaviour is dependent on the creation of conducting contacts between metallic filler particles as predicted by the percolation theory. It is suggested that good adhesion of filler-matrix and filler-filler minimise the gap between filler-filler and filler-matrix. The presence of gap may contribute to a certain degree of resistance to the conduction process.

The well distribution of epoxy composites with mixed particle size produced a well-packed composite. Therefore, percolation threshold effects easily take place as shown in Figure 7. A higher concentration of recycled copper is needed to create a conductive path throughout the entire composite (Rupprecht 1999). The absence of a transition to conducting behaviour was attributed to the broad size of filler powder which reduced the formation of continuous chains of contacting metal particles.

\section{Vickers hardness}

By referring to the Vickers hardness of the composites filled with coarse, fine and mixed recycled copper in Figure 8, it indicates that the Vickers hardness increases with the increment of the filler loading. The addition of filler will improve the composites to become more rigid

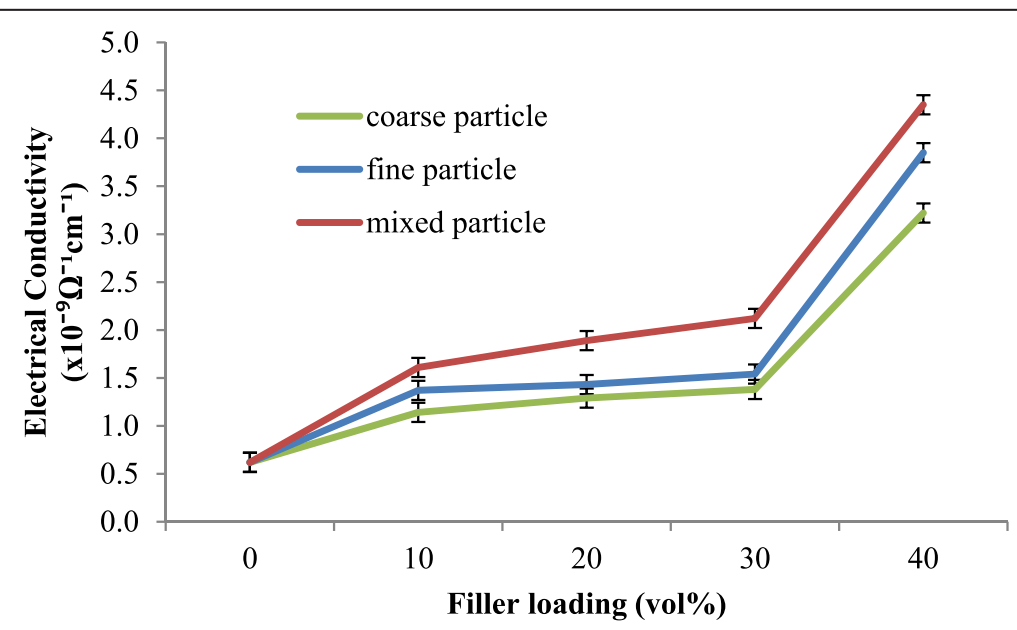

Figure 6 Electrical conductivity of epoxy composites. The epoxy composites are filled with coarse, fine and mixed particle sizes at different recycled copper filler loading. 


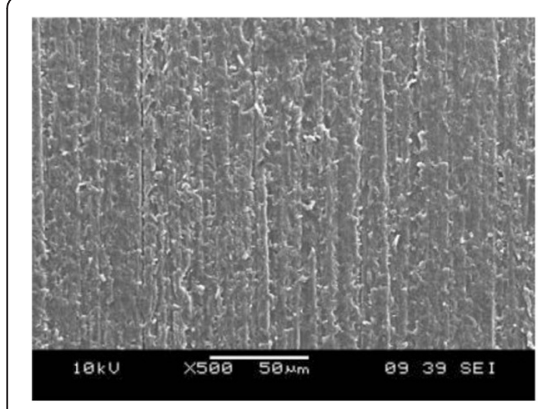

a

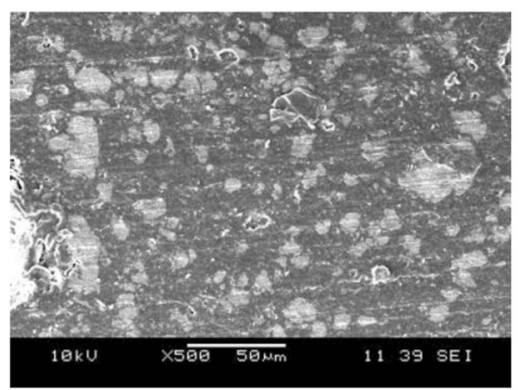

d

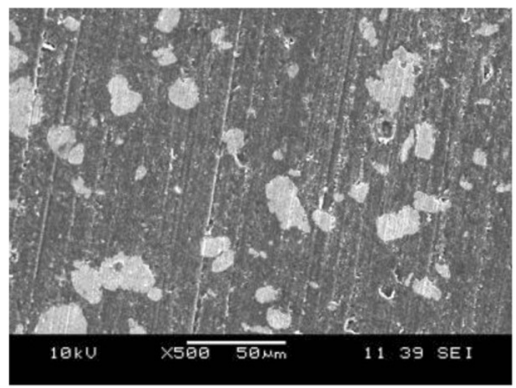

g

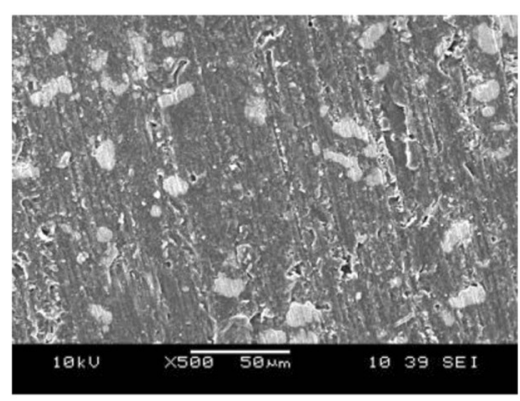

b

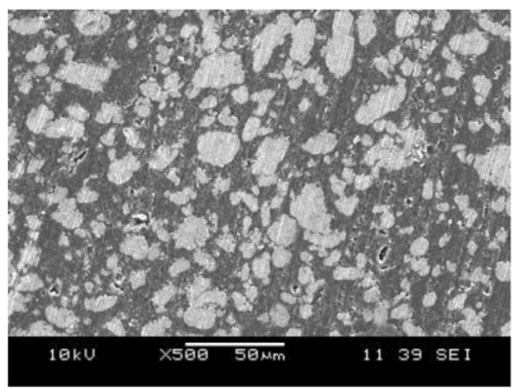

e

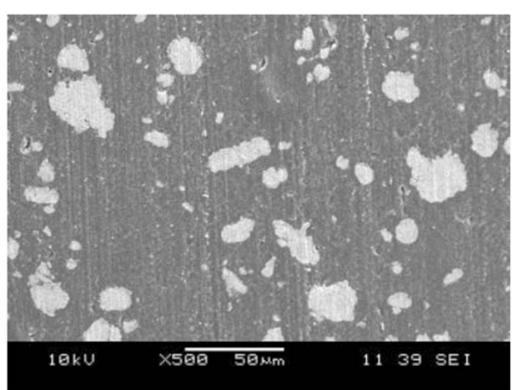

C

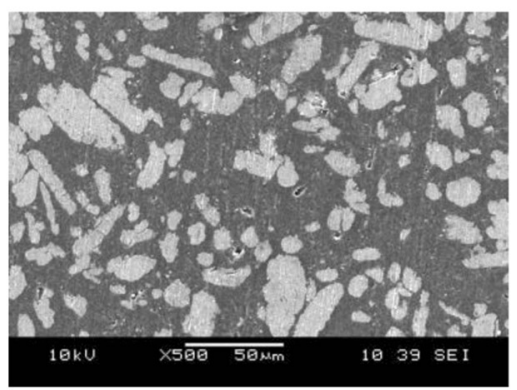

f

Figure 7 SEM of copper distribution in epoxy for epoxy composites with recycled filler content at (a) 0 vol\%, (b) coarse 20 vol\%, (c) coarse $40 \mathrm{vol} \%$, (d) fine 20 vol\%, (e) fine 40 vol\%, (f) mixed 20 vol\% and (g) mixed 40 vol\%, respectively.

of the composite. During indentation and under the same applied load, particles will collide more rapidly and distribute the stresses effectively. It serves as a blockage to resist higher magnitude of stresses prior to plastic deformation (Montoya and Pech 2007).

The fine filler caused the composites to have fewer voids since it will pack the structure (Chan et al. 2011; Suriati et al. 2011). The packed composites will strengthen the composites and therefore have high Vickers hardness value. The fine filler will tend to collide more frequently, leading to less easiness to be subjected to plastic deformation as its resistance to higher stress applied is higher. From the testing of flexural modulus, it was found that there was an increased in the stiffness of the composites resulting from the increase in filler concentration; therefore, the hardness is aligned with the flexural stiffness (Rupprecht 1999). In epoxy composites with mixed particle size, the fine filler fulfilled the space that is created by the coarse filler. This led the composites to have a better structure. During indentation and under the same applied load, particles in the composite with mixed distribution will collide more rapidly and distribute the stresses effectively. It serves as a blockage to resist higher magnitude of stresses prior to plastic deformation (Montoya and Pech 2007).

\section{Density}

The effect of different particle sizes which are coarse, fine and mixed at different filler loading on density was 


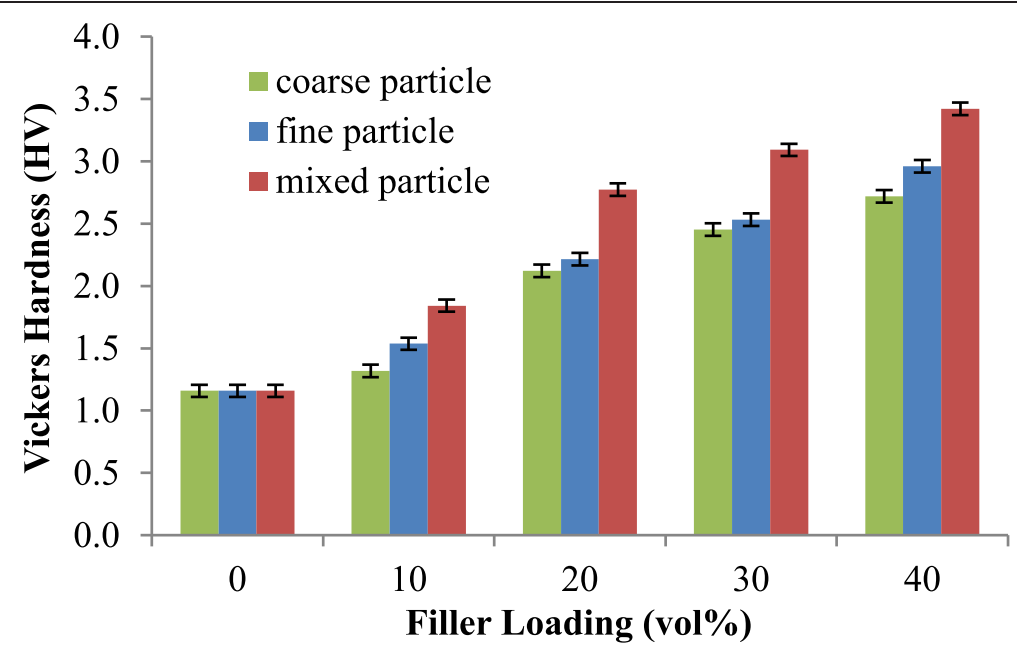

Figure 8 Vickers hardness of epoxy composites. The epoxy composites are filled with coarse, fine and mixed particle sizes at different recycled copper filler loading.

investigated. From Figure 9, it shows that epoxy composites with fine particle size have the highest density followed by mixed and coarse, respectively. The density was affected by the copper itself. Since copper has a higher density than epoxy, therefore, the density of composites will increase. The intrinsic property, which is density, is dependent on compaction and bridging phenomenon (Sided et al. 1992).

The addition of the fine filler causes the composites to have better distribution since particles distribute all around the composites. From the figure, it indicates that the recycled copper with a smaller average particle size of $10 \mu \mathrm{m}$ has a higher density than the recycled copper with a size of 300 to $400 \mu \mathrm{m}$. This difference proves that the optimal gradation factor is affected by the balanced distribution of the filler particles in the mixture achieving a maximal packing (Sided et al. 1992). At such high particle volume fractions, the processing of the material often becomes difficult, and since the inorganic filler has a higher density than the resin, the density of the filled resin is also increased. The packing behaviour of particles in a polymer matrix determines on what loading particle/particle effects become important and is a critical factor in the understanding and design of polymer composites. The maximum packing fraction can be achieved by the addition of two different particle sizes so that the void can be filled by the finer particles.

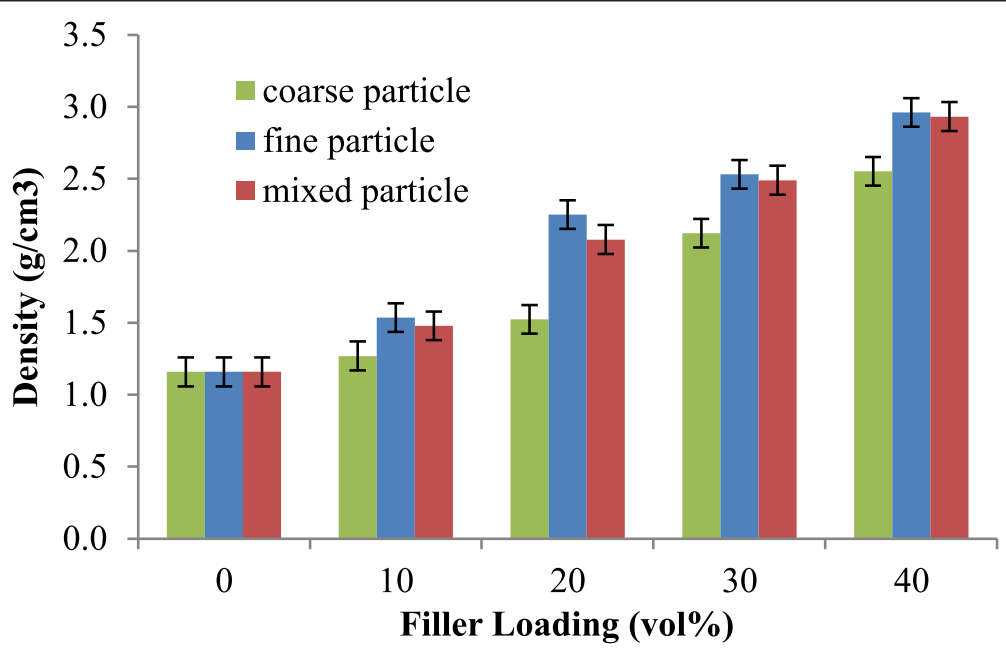

Figure 9 Density of epoxy composites. The epoxy composites are filled with coarse, fine and mixed particle sizes at different recycled copper filler loading. 


\section{Conclusions}

In overall, epoxy composites filled with mixed recycled copper content showed the best performance in term of overall properties, because had lowest CTE value and highest flexural properties, electrical conductivity, hardness and density value respectively.

\section{Competing interests}

The authors declare that they have no competing interests.

\section{Authors' contributions}

Mohamad Nur Fuadi Pargi carried out the literature on mechanical properties and drafted the paper. Teh Pei Leng was responsible on thermal expansion. Salmah Hussiensyah was responsible on physical properties of the experiment. Yeoh Cheow Keat was responsible on electrical properties and Supri Abd Ghani involved in paper alignment. All authors read and approved the final manuscript.

\section{Acknowledgements}

The financial support of the Research Acculturation Grant Scheme (RAGS) grant no.: 9003-00280 is gratefully acknowledged.

Received: 10 April 2014 Accepted: 26 January 2015

Published online: 10 March 2015

\section{References}

Battisti, A, Skordos, AA, \& Partridge, IK. (2010). Percolation threshold of carbon nanotubes filled unsaturated polyesters. Composites Science and Technology, $70,600-637$

Bhattacharya, SK. (1986). Metal-filled polymers: properties and applications. New York: Marcel Dekker.

Boudenne, A, Ibos, L, Fois, M, Majeste, JC, \& Gehin, E. (2005). Electrical and thermal behavior of polypropylene filled with copper particles. Composites, $36,1545-1554$.

Burden, AP, Guo, W, \& Hutchison, JL. (1998). Exploiting voltage contrast scanning electron microscopy to investigate conductive polymer composite resettable fuse devices. Polymer, 39, 4211-4217.

Chan, KL, Mariatti, M, Lockman, Z, \& Sim, LC. (2011). Effects of the size and filler loading on the properties of copper- and silver-nanoparticle-filled epoxy composites. Journal of Applied Polymer Science, 121, 3145-3152.

Cleveland, CJ. (2004). Encyclopedia of energy (Vol. volumes 1-6). Amsterdam: Elsevier.

Dekkers, MEJ, \& Heikens, D. (1985). Crazing and shear deformation in glass beadfilled glassy polymers. Journal of Materials Science, 20, 3873-3880.

Fekete, E, \& J Móczó, B Pukánszky. (2004). Determination of surface characteristics of particulate fillers by inverse gas chromatography at infinite dilution: a critical approach. Journal of Colloid and Interface Science, 269, 143-15.

Feller, JF, Bruzaud, S, \& Grohens, Y. (2004). Influence of clay nanofiller on electrical and rheological properties of conductive polymer composite. Materials Letters, 58, 739-745.

Gazotti, WA, Jr, Casalbore-Miceli, G, Mitzakoff, S, Geri, A, Gallazzi, MC, \& De Paoli, MA. (1999). Conductive polymer blends as electrochromic materials. Electrochimica Acta, 44, 1965-1971.

Glouannec, P, Chauvelon, P, Feller, JF, Noel, H, \& Ploteau, JP. (2008). Current passage tubes in conductive polymer composite for fluid heating. Energy Conversion and Management, 49, 493-505.

Ji, K, Xu, Y, Zhang, J, Chen, J, \& Dai, Z. (2014). Foamed-metal-reinforced composites: tribological behavior of foamed copper filled with epoxy-matrix polymer. Materials and Design, 61, 109-116.

Kitey, R, \& Tippur, HV. (2005). Role of particle size and filler-matrix adhesion on dynamic fracture of glass-filled epoxy: i. micromeasurement. Actamaterialia, $53,1153$.

Klaus, F, Zhong, Z, \& Alois, S. (2005). Effects of various fillers on the sliding wear of polymer composites. Composites Science and Technology, 65, 2329-2343.

Li, C, Zhang, L, Ding, L, Ren, H, \& Cui, H. (2011). Effect of conductive polymers coated anode on the performance of microbial fuel cells (MFCs) and its biodiversity analysis. Biosensors and Bioelectronics, 26, 4169-4176.

Lira, LM, \& de Córdoba Torresi, SI. (2005). Conducting polymer-hydrogel composites for electrochemical release devices: synthesis and characterization of semi-interpenetrating polyaniline-polyacrylamide networks. Electrochemistry Communications, 7, 717-723.

Luyt, AS, Molefi, JA, \& Krump, H. (2006). Thermal, mechanical and electrical properties of copper powder filled low-density and linear low-density polyethylene composites. Polymer Degradation and Stability, 91, 1629-1636.

Mamunya, YP, Davydenko, W, Pissis, P, \& Lebedev, EV. (2002). Electrical and thermal conductivity of polymers filled with metal powders. European Polymer Journal, 38, 1887-1897.

Michael, A, Berger, M, \& McCullough, RL. (1985). Characterization and analysis of the electrical properties of a metal-filled polymer. Composites Science and Technology, 22, 81-106.

Montoya, D, \& Pech, M. (2007). Effect of bi- and trimodal size distribution on the superficial hardness of the Al/SiCp composites prepared by pressureless infiltration. Powder Technology, 176, 66-71.

Osman, A. (2010). An experimental study on the bearing strength behaviour of $\mathrm{Al}_{2} \mathrm{O}_{3}$ particle filled glass fiber reinforced epoxy composites pinned joint. Composite Structures, 92, 354-363.

Psarras, GC. (2006). Hopping conductivity in polymer matrix-metal particles composites. Composites: Part A, 37, 1545-1553.

Ramasubramaniam, R, Chen, J, \& Liu, H. (2003). Homogeneous carbon nanotube/ polymer composites for electrical applications. Applied Physics Letters, 83, 2928-2930

Rupprecht, L (Ed.). (1999). Conductive polymers and plastics. Norwich, NY: Plastic Design Library.

Sided, A, Holdengrabe, YR, \& Buchman, A. (1992). Fundamental model for prediction of optimal particulate composite properties. Composites, $24,355-360$.

Stauffer, D, \& Aharony, A. (1985). Introduction to percolation theory. London: Taylor and Francis.

Sun, M. (2001). Conductivity of conductive polymer for flip chip bonding and BGA socket. Microelectronics Journal, 32, 197-203.

Suriati, G, Mariatti, M, \& Azizan, A. (2011). Effects of filler shape and size on the properties of silver filled epoxy composite for electronic applications. Journal of Materials Science: Materials in Electronics, 22, 56-63.

Tao, Z, Yang, S, Ge, Z, Chen, J, \& Fan, L. (2007). Synthesis and properties of novel fluorinated epoxy resins based on 1,1-bis(4-glycidylesterphenyl)-1(3'-trifluoromethylphenyl)-2,2,2-trifluoroethane. European Polymer Journal, $43,550-560$.

Tavman, HI. (1996). Thermal and mechanical properties of copper powder filled poly(ethylene) composites. Powder Technology, 91, 63-67.

Tee, DI, Mariatti, M, Azizan, A, See, CH, \& Chong, KF. (2007). Effect of silane-based coupling agent on the properties of silver nanoparticles filled epoxy composites. Composites Science and Technology, 67, 2584-2591.

Teh, PL, Ng, HT, \& Yeoh, CK. (2011). Recycled copper as the conductive filler in polyester composites. Malaysian Polymer Journal, 6, 98-108.

Willis, MR, \& Masters, I. (2003). The effect of filler loading and process route on the three-point bend performance of waste based composites. Composite Structures, 62, 475-479.

Wong, DWY, Lin, L, McGrail, PT, Peijs, T, \& Hogg, PJ. (2010). Improved fracture toughness of carbon fibre/epoxy composite laminates using dissolvable thermoplastic fibres. Composites: Part A, 41, 759-767.

$\mathrm{Xu}, \mathrm{X}, \mathrm{Kim}, \mathrm{JH}$, Yeoh, WK, Zhang, Y, \& Dou, SX. (2006). Improved Jc of MgB 2 superconductor by ball milling using different media. Superconductor Science and Technology, 19, 47-50.

\section{Submit your manuscript to a SpringerOpen ${ }^{\odot}$ journal and benefit from:}

- Convenient online submission

Rigorous peer review

- Immediate publication on acceptance

- Open access: articles freely available online

- High visibility within the field

- Retaining the copyright to your article

Submit your next manuscript at springeropen.com 